\title{
Ammonium recovery from biocatalytic calcification reactor effluent by struvite precipitation
}

\author{
Simşek I. ${ }^{1, *}$ and Altaş L. ${ }^{1}$ \\ ${ }^{1}$ Aksaray University, Engineering Faculty, Department of Environmental Engineering, 68100, Aksaray, TURKEY \\ *Corresponding author: Ismail Şimşek \\ Received: 03/08/2016, Accepted: 20/01/2017, Available online: 02/10/2017 \\ *to whom all correspondence should be addressed: \\ e-mail: ismailsimsek@aksaray.edu.tr
}

\begin{abstract}
Chemical precipitation is a suitable method for the recovery and removal of ammonium in water and a fertilizer known as MAP (magnesium ammonium phosphate; $\mathrm{MgNH}_{4} \mathrm{PO}_{4} .6 \mathrm{H}_{2} \mathrm{O}$; struvite) is obtained. Additionally, the advantage of this method is that environmental conditions do not have any effect compared to biological methods. In this study, the recovery of ammonium ( $C_{\text {mean }}=348 \mathrm{mg} \mathrm{NH}_{4}{ }^{+} / \mathrm{L} \pm 38.1$; $n=25$ ) occurred after the hydrolysis of urea in the biocatalytic calcification reactor (BCR) effluent and it precipitated as struvite. The effects of operating parameters, such as different phosphate and magnesium sources, $\mathrm{Mg}^{2+}: \mathrm{NH}_{4}{ }^{+}: \mathrm{PO}_{4}{ }^{3-}$ molar ratio, $\mathrm{pH}$ value, mixing speed-time, and fertilizer effect, were examined. The precipitates were characterized by X-ray diffraction and scanning electron micrograph. The optimum molar ratio of $\mathrm{Mg}^{2+}: \mathrm{NH}_{4}{ }^{+}: \mathrm{PO}_{4}{ }^{3-}$ was determined as 1.25:1:1. Studies using different $\mathrm{pH}$ ranges (7-10) and this molar ratio showed that the ammonium recovery of approximately $96 \%$ was reached at a $\mathrm{pH}$ value of 9.36 . It was seen that the rapid mixing $(200 \mathrm{rpm})$ of 30 -s period and the slow mixing $(30 \mathrm{rpm}$ ) of 2-min period were sufficient for MAP precipitation. Struvite that was obtained after precipitation was used as a fertilizer and it was observed to have a positive effect on plant growth.
\end{abstract}

Keywords: Ammonium Recovery, Biocatalytic Calcification, Chemical Precipitation, Fertilizer, Struvite.

\section{Introduction}

Nitrogen compounds are nutrients essential to all forms of life and when present in considerable quantities in receiving waters such as lakes and rivers they can cause eutrophication, resulting in excessive growth of algae and other microorganisms, as well as increased dissolved oxygen depletion and fish toxicity (Huang et al., 2010a). Therefore, the removal of ammonium from wastewater is of great importance in the control of nitrogen pollution (Thornton et al., 2007; Wen et al., 2006). High content of ammonia nitrogen has a toxic effect on microorganisms, which may lead to a decrease in the treatment efficiency of the biological process (Huang et al., 2011). Struvite precipitation is a valid alternative for the removal of high ammonia concentrations such as piggery wastes due to its high removal effectiveness, reaction rate, and solid-liquid separation capability (Huang et al., 2011). In addition, struvite could be directly used for horticulture and agriculture, such as potato production, and even used for fish farming, like trout and salmon population conservation (Wang et al., 2010). Reaction of ammonium ions with phosphate and magnesium ions to form struvite, which is a white orthorhombic mineral with a crystalline structure and a precipitate with a very low solubility product $\left(2.5 \times 10^{-13}, 25^{\circ} \mathrm{C}\right)$ (Huang et al., 2014; Lee et al., 2003; Macintyre, 1996; Zhang et al., 2004), has attracted much attention because of the extremely high reaction rates and low residual ammonium concentrations. The reaction is shown in Equation 1 (Zhang et al., 2004).

$$
\mathrm{Mg}^{2+}+\mathrm{NH}_{4}^{+}+\mathrm{PO}_{4}^{3-}+6 \mathrm{H}_{2} \mathrm{O} \rightarrow \mathrm{MgNH}_{4} \mathrm{PO}_{4} \cdot 6 \mathrm{H}_{2} \mathrm{O} \downarrow
$$

Struvite precipitation was commonly used in different processes such as raw swine wastewater (Lin et al., 2015), anaerobic digestate effluent (Hidalgo et al., 2016), sewage sludge ash (Xu et al., 2012), urine (Antonini et al., 2011; Kemacheevakul et al., 2014; Latifian et al., 2014; Zhigang et al., 2008), washing wastewater (Huang et al., 2010b), and reject water of sludge thickening and dewatering (Ren et al., 2015).

In literature, there is a lack of knowledge about MAP precipitation in the biocatalytic calcification reactor (BCR) effluent, so in this study, physical and chemical parameters, which are effective in MAP precipitation, were investigated. The working principle of the recovery of ammonium ( $\mathrm{C}_{\text {mean }}=348 \mathrm{mg} \mathrm{NH}_{4}{ }^{+} / \mathrm{L} \pm 38,1 ; \mathrm{n}=25$ ) in the biocatalytic calcification reactor $(B C R)$ effluent is to precipitate $\mathrm{Ca}$ as $\mathrm{CaCO}_{3}$ by creating a high $\mathrm{pH}$ and alkalinity with the addition of urea. Effluent values of ammonium concentration clarified that urea was mostly transformed into ammonium in the process (Işik et al., 2010). Magnesium and phosphate required for precipitation were provided from different chemical sources. Optimum molar ratio of $\mathrm{Mg}^{2+}: \mathrm{NH}_{4}{ }^{+}: \mathrm{PO}_{4}{ }^{3-}$ was determined. Studies using different $\mathrm{pH}$ ranges (7-10), 
mixing rapid and period, used this molar ratio. Struvite obtained after precipitation was used as a fertilizer and it was observed that struvite has a positive effect on plant growth.

\section{Materials and Methods}

\subsection{Wastewaters and chemicals}

The wastewater of BCR effluent was used in the experiments. Some parameters of the wastewater sample are given in Table 1. In this study, pure $\mathrm{MgCl}_{2} .6 \mathrm{H}_{2} \mathrm{O}, \mathrm{MgO}$, $\mathrm{MgSO}_{4} .7 \mathrm{H}_{2} \mathrm{O}, \quad \mathrm{NaH}_{2} \mathrm{PO}_{4} .2 \mathrm{H}_{2} \mathrm{O}, \mathrm{H}_{3} \mathrm{PO}_{4}$ (\%85), and $\mathrm{CaHPO}_{4} .2 \mathrm{H}_{2} \mathrm{O}$ were used as the magnesium and phosphate sources. During the struvite reaction, the $\mathrm{pH}$ of the solution was adjusted to the desired value by the addition of $2 \mathrm{~N} \mathrm{NaOH}$.
All the experiments were carried out in triplicate at a wastewater temperature ranging from 20 to $25{ }^{\circ} \mathrm{C}$. The experiments of MAP precipitation were carried out in 500 $\mathrm{mL}$ of wastewater in $600 \mathrm{~mL}$ beakers batchwise. The amounts of $\mathrm{Mg}^{2+}$ and $\mathrm{PO}_{4}{ }^{3-}$ sources were added according to initial concentrations. The $\mathrm{Mg}^{2+}: \mathrm{NH}_{4}{ }^{+}: \mathrm{PO}_{4}{ }^{3-}$ molar ratio was initially adjusted by adding the appropriate quantity of chemicals, which is mentioned in the material section. Coagulation (200 rpm, $2 \mathrm{~min}$ ) and flocculation (30 rpm, 5 min) were applied with jar test (Velp, FC6S). After 10 minutes of settling, the supernatant sample was taken and analyzed (Figure 1). According to results, $\mathrm{MgCl}_{2} \cdot 6 \mathrm{H}_{2} \mathrm{O}$ and $\mathrm{H}_{3} \mathrm{PO}_{4}$ (\%85) were used as the magnesium and phosphate sources to determine optimum $\mathrm{Mg}^{2+}: \mathrm{NH}_{4}{ }^{+}: \mathrm{PO}_{4}{ }^{3-}$ molar ratio, $\mathrm{pH}$, mixing speed, and time.

\subsection{Struvite precipitation experiments}

Table 1. Some parameters of wastewater

\begin{tabular}{ccccccccccc}
\hline Parameters & $\mathbf{p H}$ & $\begin{array}{c}\mathrm{TOC} \\
(\mathbf{m g} / \mathrm{L})\end{array}$ & $\begin{array}{c}\mathrm{TN} \\
(\mathbf{m g} / \mathrm{L})\end{array}$ & $\begin{array}{c}\mathrm{NH}_{4}-\mathrm{N} \\
(\mathbf{m g} / \mathrm{L})\end{array}$ & $\begin{array}{c}\mathrm{PO}_{4}-\mathrm{P} \\
(\mathbf{m g} / \mathrm{L})\end{array}$ & $\begin{array}{c}\mathrm{Na} \\
(\mathbf{m g} / \mathrm{L})\end{array}$ & $\begin{array}{c}\mathrm{K} \\
(\mathbf{m g} / \mathrm{L})\end{array}$ & $\begin{array}{c}\mathrm{Ca} \\
(\mathbf{m g} / \mathrm{L})\end{array}$ & $\begin{array}{c}\mathrm{Mg} \\
(\mathbf{m g} / \mathrm{L})\end{array}$ & $\begin{array}{c}\mathrm{Turbidity} \\
(\mathbf{N T U})\end{array}$ \\
\hline Mean & 8.37 & 56.43 & 279.17 & 270.21 & 6.71 & 352.08 & 27.04 & 3.44 & 90.95 & 54.66 \\
SD $( \pm)$ & 0.18 & 19.6 & 30.02 & 28.43 & 1.58 & 55.41 & 2.21 & 5.62 & 15.17 & 20.6 \\
\hline
\end{tabular}

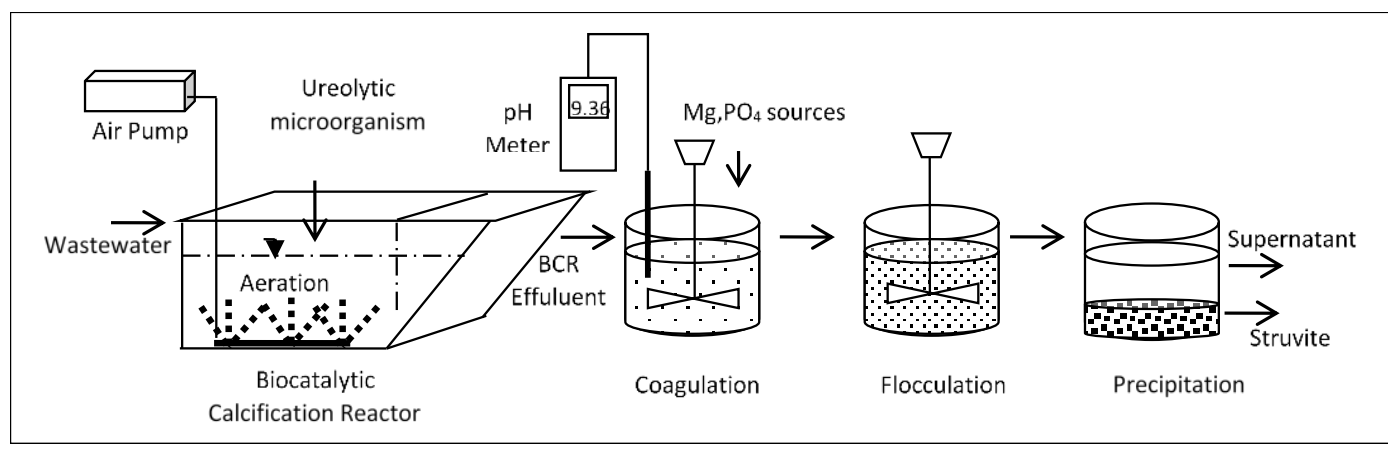

Figure 1. Schematic diagram

\subsection{Evaluation of collected struvite as a fertilizer}

To evaluate struvite, 200 gram of raw soil was taken from an upland area in Aksaray and sieved with a maximum aperture size of $3 \mathrm{~mm}$ prior to filling 8 pots. Two seeds of pepper (capsicum) plants were planted in the top $1.0 \mathrm{~cm}$ of soil, and different dry weights of struvite were added in each pot. The room temperature of laboratory was between 20 and $25{ }^{\circ} \mathrm{C}$ during the experimental period. 20 $\mathrm{mL}$ of distilled water was poured in each pot every 2 days. Plant growth has been observed in 75 days.

\subsection{Analytical methods}

The measurements of ammonium $\left(\mathrm{NH}_{4}-\mathrm{N}\right)$ (SM: 4500-NH3 D), phosphate $\left(\mathrm{PO}_{4}-\mathrm{P}\right)$ (Dionex ICS-1000 Ion Chromatography) (SM: 4110 B), turbidity (SM: 2130 B), total organic carbon (TOC) (EN: 1484), and total nitrogen (TN) (EN: 12260) (Shimadzu TOC-V $\mathrm{V}_{\text {CPN }} / T N M-1$ ) were implemented in wastewater. The $\mathrm{pH}$ of wastewater samples was measured by a $\mathrm{pH}$ meter (ORION) (SM: 4500$\left.\mathrm{H}^{+} \mathrm{B}\right)$. $\mathrm{Na}, \mathrm{Ca}, \mathrm{Mg}$, and $\mathrm{K}$ were measured using an Inductively Coupled Plasma-Optical Emission
Spectrometer (SM 3120 B) (Perkin Elmer, Optima 2100 DV) (APHA, 2005). The collected precipitate was washed thrice with ultrapure water, dried in an oven at $35^{\circ} \mathrm{C}$ for $24 \mathrm{~h}$, and then characterized by a scanning electron microscopy (SEM) (FEI Quanta 400 MK2) and X-ray diffraction (XRD) (Inel equinox 1000).

\section{Results and Discussion}

3.1. The usage of different phosphate and magnesium sources

Extra doses of different magnesium $\left(\mathrm{MgCl}_{2} .6 \mathrm{H}_{2} \mathrm{O}, \mathrm{MgO}\right.$, $\left.\mathrm{MgSO}_{4} .7 \mathrm{H}_{2} \mathrm{O}\right)$ and phosphate $\left(\mathrm{NaH}_{2} \mathrm{PO}_{4} .2 \mathrm{H}_{2} \mathrm{O}, \mathrm{H}_{3} \mathrm{PO}_{4}\right.$, $\mathrm{CaHPO}_{4} .2 \mathrm{H}_{2} \mathrm{O}$ ) sources were added to $\mathrm{BCR}$ effluent that contains sufficient ammonium concentrations in contrast to low magnesium and phosphate concentrations to satisfy the stoichiometric requirement of struvite formation.

As shown in Figure 2, the maximum ammonium recovery efficiency was provided by $\mathrm{MgCl}_{2} .6 \mathrm{H}_{2} \mathrm{O}$ and $\mathrm{NaH}_{2} \mathrm{PO}_{4} .2 \mathrm{H}_{2} \mathrm{O}$. However, the recovery efficiencies of $\mathrm{NaH}_{2} \mathrm{PO}_{4} .2 \mathrm{H}_{2} \mathrm{O}$ and $\mathrm{H}_{3} \mathrm{PO}_{4}$ were the same. For economic 
reasons, in order to achieve the same concentration of $\mathrm{PO}_{4}$ the $\mathrm{H}_{3} \mathrm{PO}_{4}\left(61 € / \mathrm{kgPO}_{4}\right)$ is used as it is cheaper than $\mathrm{NaH}_{2} \mathrm{PO}_{4} .2 \mathrm{H}_{2} \mathrm{O}$ (98€/kgPO 4$)$. Therefore, $\mathrm{H}_{3} \mathrm{PO}_{4}$ and $\mathrm{MgCl}_{2} .6 \mathrm{H}_{2} \mathrm{O}$ are chosen.

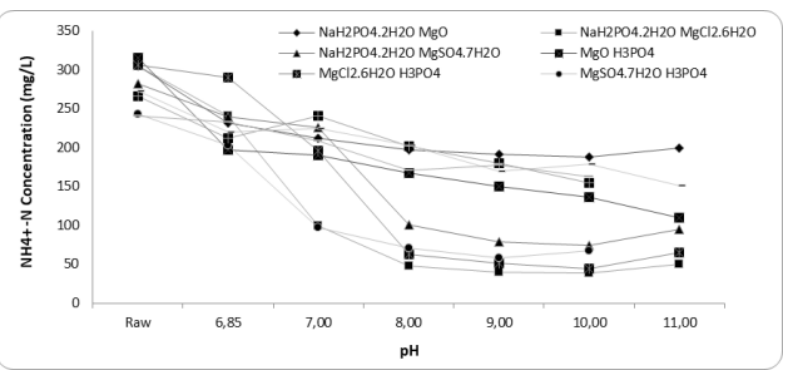

Figure 2. The usage of different phosphate and magnesium sources in precipitation.

3.2. The effect of $\mathrm{Mg}^{2+}: \mathrm{NH}_{4}^{+}: \mathrm{PO}_{4}{ }^{3-}$ molar ratio to precipitation

In the first part, we investigate the effect of $\mathrm{Mg}^{2+}: \mathrm{NH}_{4}{ }^{+}$ molar ratio on the precipitation (Figure 3); 2.25:1 ratio was obtained for the maximum efficiency of recovery. The recovery efficiency was very close for the ratios 2.25:1 and 1.25:1. Therefore, we took the molar ratio $1.25: 1$ and also reduced the magnesium concentration twice. Thus, the molar ratio $1.25: 1$ is opted.

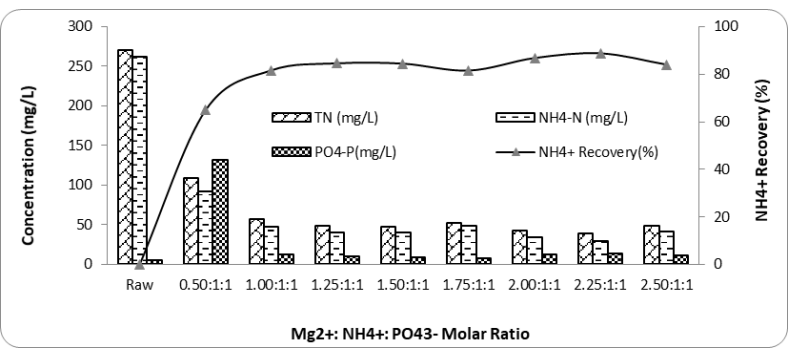

Figure 3. The effect of $\mathrm{Mg}^{2+:} \mathrm{NH}_{4}{ }^{+}$molar ratio to precipitation.

As shown in Figure 3, the ammonium recovery increased from $64.9 \%$ to $88.8 \%$ when the $\mathrm{Mg}^{2+}: \mathrm{NH}_{4}{ }^{+}$molar ratio increased from 0.5:1 to 2.25:1. However, any excess of $\mathrm{Mg}$ concentration over the $1.25: 1$ ratio did not result in the extreme increase in ammonium recovery. Figure 4 shows that $\mathrm{PO}_{4}{ }^{3-}$ shortage in the solution is very important for the formation of MAP, and this was corroborated by Huang et al., (2012).

As the molar ratio of phosphate increases, ammonium recovery efficiency also increased in the second part of the study that affected the $\mathrm{NH}_{4}{ }^{+}: \mathrm{PO}_{4}{ }^{3-}$ molar ratio and hence the precipitation. In contrast, the amount of nutrient is also increased. So, $\mathrm{Mg}^{2+}: \mathrm{NH}_{4}{ }^{+}: \mathrm{PO}_{4}{ }^{3-}$ molar ratio 1.25:1:1 is preferred.

3.3. The effect of $p H$ on precipitation of 1.25:1:1 $\mathrm{Mg}^{2+}: \mathrm{NH}_{4}^{+}: \mathrm{PO}_{4}{ }^{3-}$ molar ratio

$\mathrm{pH}$ of wastewater is very important for MAP precipitation because the activities of both $\mathrm{NH}_{4}{ }^{+}$and $\mathrm{PO}_{4}{ }^{3-}$ are $\mathrm{pH}$ dependent. Published values for the $\mathrm{pH}$ of minimum struvite solubility range from 9 to 10.7 (Nelson et al., 2003).

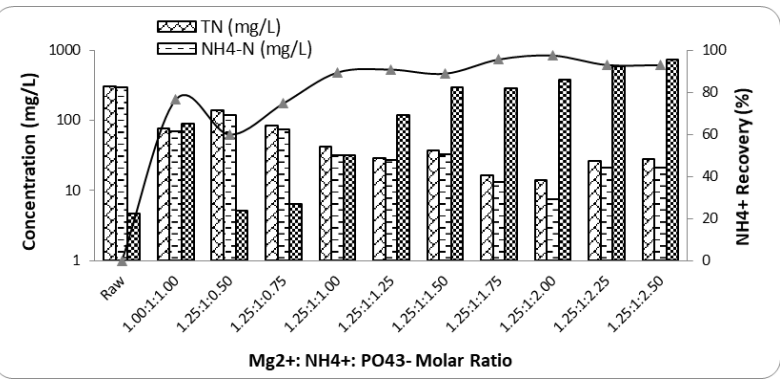

Figure 4. The effect of $\mathrm{NH}_{4}^{+}$: $\mathrm{PO}_{4}^{3-}$ molar ratio to precipitation

At the optimum molar ratio (1.25:1:1), to determine the maximum recovery efficiency, the different $\mathrm{pH}$ values are studied. When the $\mathrm{pH}$ was higher than the optimum point, $\mathrm{Mg}_{3}\left(\mathrm{PO}_{4}\right)_{2}$ was formed instead of MAP with $\mathrm{pH}$ increased, which led to the decrease of the ammonium removal ratio (Zhang et al., 2009); moreover, ammonium ions convert to ammonia at a high $\mathrm{pH}$.

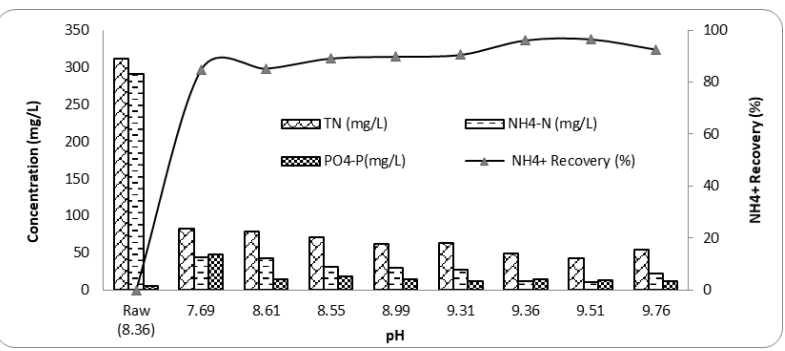

Figure 5. The effect of $\mathrm{pH}$ on precipitation of 1.25:1:1 $\mathrm{Mg}^{2+:} \mathrm{NH}_{4}^{+}: \mathrm{PO}_{4}{ }^{3-}$ molar ratio

As shown in Figure 5, the maximum recovery occurs at $\mathrm{pH}$ 9.36 (96\%). This may be due to the decomposition of struvite crystallization in the wastewater when the $\mathrm{pH}$ was decreased below the optimum point, thereby causing a decrease of the ammonium recovery ratio.

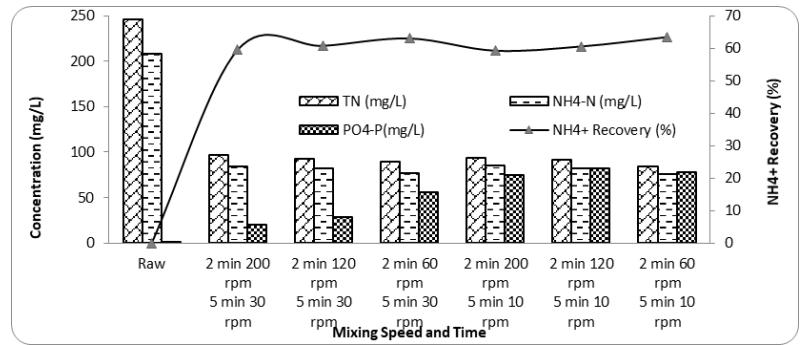

Figure 6(a). The effect of mixing speed and time to precipitation

As the molar ratio of phosphate increases, ammonium recovery efficiency also increased in the second part of the study that affected the $\mathrm{NH}_{4}{ }^{+}: \mathrm{PO}_{4}{ }^{3-}$ molar ratio and hence the precipitation. In contrast, the amount of nutrient is also increased. So, $\mathrm{Mg}^{2+}: \mathrm{NH}_{4}{ }^{+}: \mathrm{PO}_{4}{ }^{3-}$ molar ratio 1.25:1:1 is preferred. 
In Figure 6 (a) and 6 (b), the different mixing speed and time are investigated. According to the results, the same maximum removal efficiency is obtained at (30 s $200 \mathrm{rpm}$, $2 \mathrm{~min} 30 \mathrm{rpm}$ ), (30 s $200 \mathrm{rpm}, 1 \mathrm{~min} 30 \mathrm{rpm}$ ), and (3 $\mathrm{min} 60 \mathrm{rpm}, 3 \mathrm{~min} 10 \mathrm{rpm}$ ). In consideration of the economic incomes and phosphate concentrations (8.35, $10.36,13.46 \mathrm{mgPO}_{4}-\mathrm{P} / \mathrm{L}$, respectively) after precipitation in supernatant, the optimum mixing speed and time, $30 \mathrm{~s}$ $200 \mathrm{rpm}, 2 \mathrm{~min} 30 \mathrm{rpm}$, is chosen. Stratful et al., (2001) corroborated that the increase of mixing time from 1 to $180 \mathrm{~min}$ has a negligible effect on the production of struvite.

\subsection{Evaluation of collected struvite as a fertilizer}

SEM images of the struvite precipitates were taken that showed the presence of needle-shaped crystalline products of diameter 50-100 $\mu \mathrm{m}$ (Figure 7).

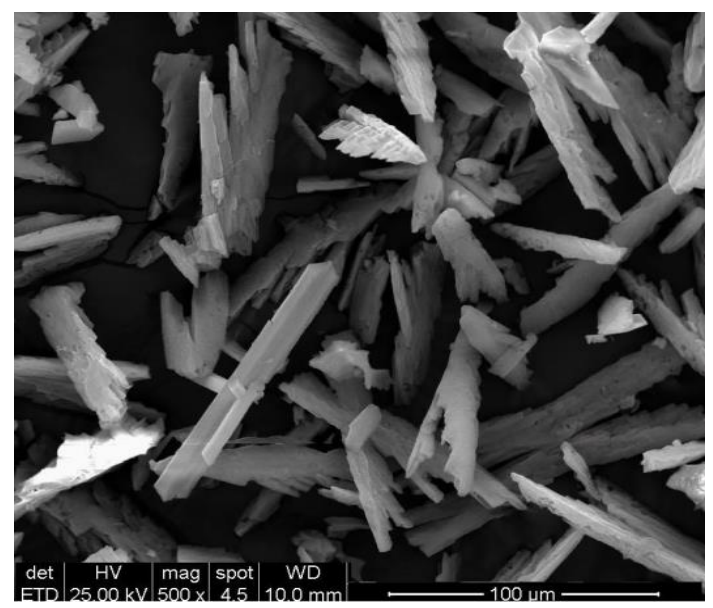

XRD analysis indicated that the precipitate peaks were suitable for those of the struvite standard pattern as you can see in Figure 8.

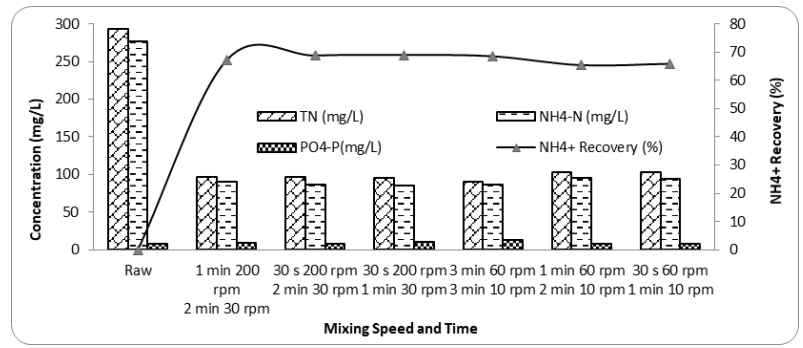

Figure $\mathbf{6}(\mathbf{b})$. The effect of mixing speed and time to precipitation

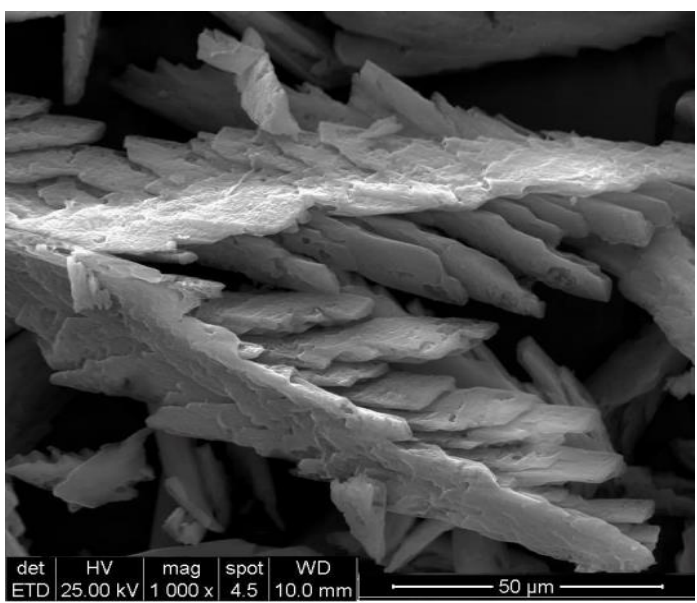

Figure 7. SEM photographs of the precipitates

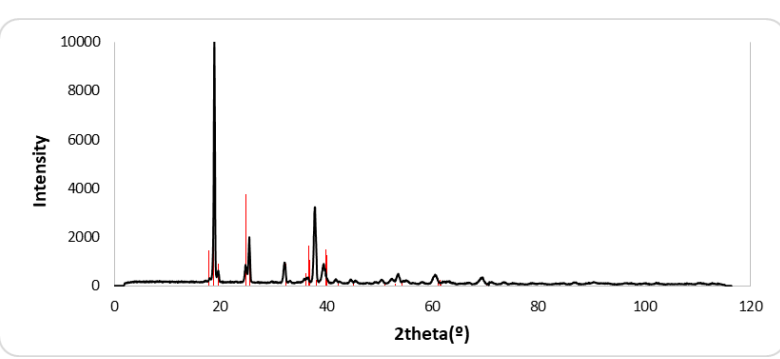

Figure 8. X-ray diffraction analysis of the precipitates

To evaluate struvite, 200 gram of raw soil was sieved to fill 8 pots. Two seeds of pepper (capsicum) plants were planted and different dry weights of struvite were added in each pot. No struvite is added in the first and second pots. 0.5-1-2.5-5-7.5-10 grams of struvite are added in the other pots, respectively.

As shown in Figure 9, plants numbered 4, 5, and 6 grow faster and bloom earlier than the others. Controlled struvite precipitation may not only reduce the load of phosphorus and ammonia returned to the mainstream treatment process but also produce a valuable and marketable fertilizer (Kruk et al., 2014). The presence of magnesium makes struvite useful for crops that need this ion, such as sugar beets (De-Bashan, Bashan, 2004; Pastor et al., 2008).

\section{Conclusions}

The recovery of ammonia from the wastewater with MAP precipitation is preferred because of economical and environmental conditions compared to biological nutrient removal methods. MAP precipitation was investigated for ammonia recovery from the BCR effluents. The results showed that a satisfactory ammonia recovery $(96 \%, \mathrm{pH}$ 9.36) could be achieved when a mixture of $\mathrm{H}_{3} \mathrm{PO}_{4}$ and $\mathrm{MgCl}_{2} .6 \mathrm{H}_{2} \mathrm{O}$ was applied for chemical precipitation at a

$\mathrm{Mg}^{2+}: \mathrm{NH}_{4}{ }^{+}: \mathrm{PO}_{4}{ }^{3-}$ molar ratio of 1.25:1:1 in $30 \mathrm{~s} 200 \mathrm{rpm}, 2$ min $30 \mathrm{rpm}$ mixing time and speed. Although $96 \%$ recovery efficiency was achieved, a little increase of phosphate concentration due to the addition of phosphoric acid as a phosphate source was seen. Therefore, phosphate can be used as a nutrient in the receiving environment. This point should not be ignored.

Although phosphate concentration was increased slightly as a result of MAP precipitation as supernatant, phosphate (1500-1600 mg/L PO ${ }_{4}^{3-}$ ) was added to achieve a molar ratio that recovered $99 \%$ of the struvite. MAP precipitation process can be accomplished in a high 
ammonium as well as a high phosphate concentration, and this is a cost-effective method. Finally, struvite can be

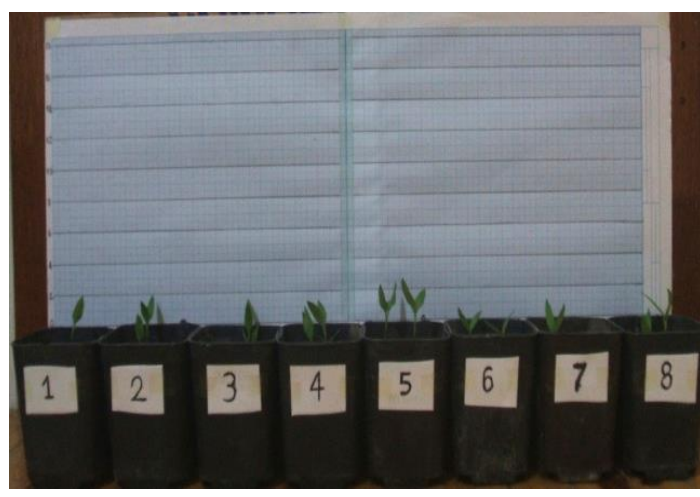

A. 15.Days

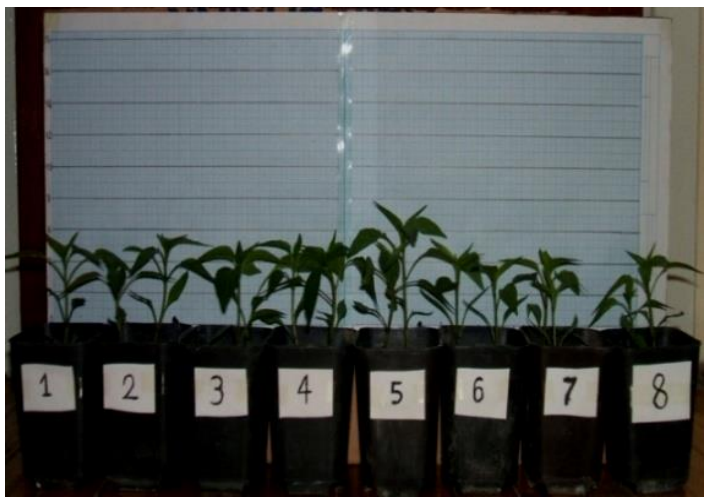

C. 45.Days used as a fertilizer for plant growth if it does not contain heavy metals and toxic substances.

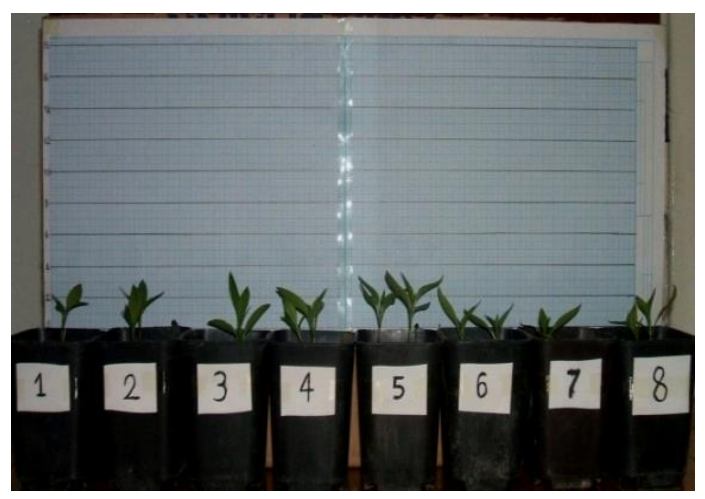

B. 25.Days

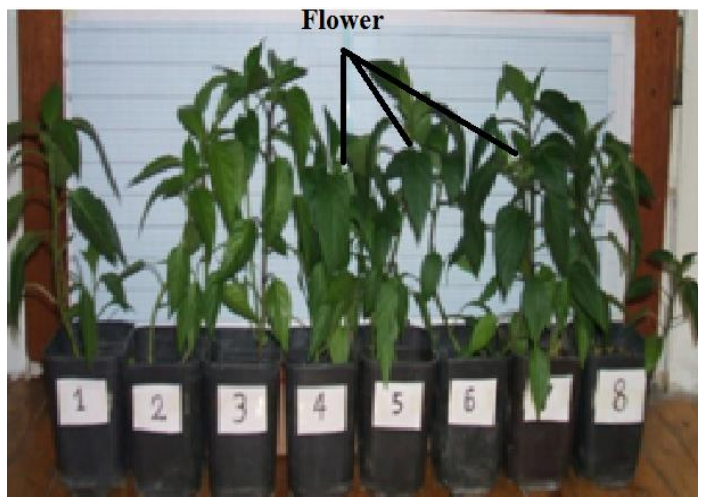

D. 75.Days

Figure 9. Photographs of pepper (capsicum) plants

\section{Acknowledgements}

This work was supported by The Scientific and Technological Council of Turkey (TUBITAK) through Grant Number $105 Y 262$.

\section{References}

Antonini S., Paris S., Eichert T. and Clemens J. (2011), Nitrogen and phosphorus recovery from human urine by struvite precipitation and air stripping in Vietnam, Clean-Soil, Air, Water, 39(12), 1099-1104.

APHA (2005), Standard methods for the examination of water and wastewater, American Public Health Association (ALPHA): Washington, DC, USA.

De-Bashan L.E. and Bashan Y. (2004), Recent advances in removing phosphorus from wastewater and its future use as fertilizer (1997-2003), Water Research, 38(19), 4222-4246.

Hidalgo D., Corona F., Martín-Marroquín J.M., del Álamo J. and Aguado A. (2016), Resource recovery from anaerobic digestate: struvite crystallisation versus ammonia stripping, Desalination and Water Treatment, 57(6), 2626-2632.

Huang H., Chen Y., Jiang Y. and Ding L. (2014), Treatment of swine wastewater combined with $\mathrm{MgO}$ saponification wastewater by struvite precipitation technology, Chemical Engineering Journal, 254, 418-425.
Huang H., Song Q., Wang W., Wu S. and Dai J. (2012), Treatment of anaerobic digester effluents of nylon wastewater through chemical precipitation and a sequencing batch reactor process, Journal of Environmental Management, 101, 68-74.

Huang H., Xiao X., Yan B. and Yang L. (2010a), Ammonium removal from aqueous solutions by using natural Chinese (Chende) zeolite as adsorbent, Journal of Hazardous materials, 175(1), 247-252.

Huang H., Xiao X., Yang L. and Yan B. (2010b), Removal of ammonia nitrogen from washing wastewater resulting from the process of rare-earth elements precipitation by the formation of struvite, Desalination and Water Treatment, 24(1-3), 85-92.

Huang H., Xu C. and Zhang W. (2011), Removal of nutrients from piggery wastewater using struvite precipitation and pyrogenation technology, Bioresource Technology, 102(3), 2523-2528.

Işık M., Altaş L., Kurmaç Y., Özcan S. and Oruç Ö. (2010), Effect of hydraulic retention time on continuous biocatalytic calcification reactor, Journal of Hazardous Materials, 182(1), 503-506.

Kemacheevakul P., Chuangchote S., Otani S., Matsuda T. and Shimizu Y. (2014), Phosphorus recovery: minimization of amount of pharmaceuticals and improvement of purity in struvite recovered from hydrolysed urine, Environmental Technology, 35(23), 3011-3019. 
Kruk D.J., Elektorowicz M. and Oleszkiewicz J.A. (2014), Struvite precipitation and phosphorus removal using magnesium sacrificial anode, Chemosphere, 101, 28-33.

Latifian M., Holst O. and Liu J. (2014), Nitrogen and phosphorus removal from urine by sequential struvite formation and recycling process, Clean-Soil, Air, Water, 42(8), 1157-1161.

Lee S., Weon S., Lee C. and Koopman B. (2003), Removal of nitrogen and phosphate from wastewater by addition of bittern, Chemosphere, 51(4), 265-271.

Lin Q., Chen Z., Liu J., Tang B., Ye J. and Zhang L. (2015), Optimization of struvite crystallization to recover nutrients from raw swine wastewater, Desalination and Water Treatment, 56(11), 3106-3112.

Macintyre J.E. (1996), Dictionary of Inorganic Compounds,CRC Press.

Nelson N.O., Mikkelsen R.L. and Hesterberg D.L. (2003), Struvite precipitation in anaerobic swine lagoon liquid: effect of $\mathrm{pH}$ and $\mathrm{Mg}$ : $\mathrm{P}$ ratio and determination of rate constant, Bioresource Technology, 89(3), 229-236.

Pastor L., Mangin D., Barat R. and Seco A. (2008), A pilot-scale study of struvite precipitation in a stirred tank reactor: conditions influencing the process, Bioresource Technology, 99(14), 6285-6291.

Ren W., Zhou Z., Wan L., Hu D., Jiang L. M. and Wang L. (2015), Optimization of phosphorus removal from reject water of sludge thickening and dewatering process through struvite precipitation, Desalination and Water Treatment, 1-9.

Stratful I., Scrimshaw M. and Lester J. (2001), Conditions influencing the precipitation of magnesium ammonium phosphate, Water Research, 35(17), 4191-4199.

Thornton A., Pearce P. and Parsons S. (2007), Ammonium removal from solution using ion exchange on to MesoLite, an equilibrium study, Journal of Hazardous Materials, 147(3), 883-889.

Wang C.C., Hao X.D., Guo G.S. and Van Loosdrecht M. (2010), Formation of pure struvite at neutral $\mathrm{pH}$ by electrochemical deposition, Chemical Engineering Journal, 159(1), 280-283.

Wen D., Ho Y.S. and Tang X. (2006), Comparative sorption kinetic studies of ammonium onto zeolite, Journal of Hazardous Materials, 133(1), 252-256.

Xu H., He P., Gu W., Wang G. and Shao L. (2012), Recovery of phosphorus as struvite from sewage sludge ash, Journal of Environmental Sciences, 24(8), 1533-1538.

Zhang S., Yao C., Feng X. and Yang M. (2004), Repeated use of $\mathrm{MgNH}_{4} \mathrm{PO}_{4} 6 \mathrm{H}_{2} \mathrm{O}$ residues for ammonium removal by acid dipping, Desalination, 170(1), 27-32.

Zhang T., Ding L., Ren H. and Xiong X. (2009), Ammonium nitrogen removal from coking wastewater by chemical precipitation recycle technology, Water Research, 43(20), 5209-5215.

Zhigang L., Qinglian, Z., Kun W., Duujong L., Wei Q. and Jianfang W. (2008), Urea hydrolysis and recovery of nitrogen and phosphorous as MAP from stale human urine, Journal of Environmental Sciences, 20(8), 1018-1024. 